\title{
Design Study of Piezoelectric Micro-machined Mechanically Coupled Cantilever Filters using a Combined Finite Element and Microwave Circuit Analysis
}

\author{
Meiling Zhu* and Paul B. Kirby \\ Cranfield University \\ *Corresponding author address: Building 70, School of Industrial and Manufacturing Science \\ Cranfield University, Cranfield, Bedfordshire, MK43 0AL, UK \\ Tel:+44 (01234) 750111 ext. 2580, Fax: +44 (01234) 751346, email:m.zhu@cranfield.ac.uk
}

\begin{abstract}
A new mechanical filter structure is presented which comprises two silicon cantilevers mechanically coupled by a silicon linkage with thin film piezoelectric transducers providing electrical input and output signals. The resonance behaviour of such a structure results in a bandpass filter response, having a band-width determined by the frequency separation between the closely spaced in-phase and out-of-phase vibrational modes of the two coupled cantilevers. A detailed configuration design analysis, filter simulation and optimisation of performance is undertaken using a new modelling approach combining microwave circuit theory and finite element analysis to evaluate the generalised $(A, B, C$ and $D)$ and scattering $(S)$ circuit parameters of the filter. Two significant features of the filters have emerged from the derived analyses and simulations: (1) with correct design filter $Q$-values can reach several thousand which is much higher than the $Q$-values ( 80) of uncoupled cantilevers, (2) the $Q$-value is determined by the configuration of the silicon linkage and so is under the designer's control. The position and length of the linkage that give optimum $\mathrm{Q}$ and minimum insertion loss are determined.
\end{abstract}

Key words: coupled cantilevers, piezoelectric mechanical filters, microwave circuit, FEA 


\section{Introduction}

RF and microwave MEMS components such as switches, varactors, resonators and filters have widespread potential applications in the telecommunications industry because of their superior performance compared to conventional semiconductor devices [1, 2]. One of the particular attractions is the possibility of integrating passive components with silicon integrated circuits for mobile communications. There has been a great deal of research effort worldwide over the last decade aimed at developing new RF MEMS piezoelectrically actuated components. The most notable recent piezoelectric filter designs are based on the thin film bulk acoustic resonator (FBAR) [3], where the resonant frequency is determined mainly by the thickness of the piezolayer. Since this thickness is fixed during deposition of the piezo-layer, it is difficult to fabricate FBARs with multiple frequencies on a single chip [4]. For the device considered in this paper the resonant frequency is not only determined by the thickness of the moving element, but also by in-plane dimensions which can be easily varied across a wafer. Furthermore, some applications require high- $Q$ filters with very steep filter skirts but in most cases the $Q$-value of the filters is limited by the $Q$ of the individual resonators that make up the filter. This paper analyses a new type of filter where the $Q$-value is mainly determined by the structural configuration. The new structure is composed of two silicon cantilevers having thin film PZT transducers defined on their top surface which are mechanically coupled by a silicon linkage. Such a coupled cantilever system exhibits a series of closely spaced in-phase and out-of-phase vibrational modes which define the filter pass-band.

Several approaches can be used to model miniature mechanical filters, including lumped massspring [5], equivalent electrical circuit [6], [7], finite element analysis (FEA) [4], [8], [9], and acoustic transmission line [10]. Lumped mass-spring modelling does give a deep understanding 
of structural design but it involves many assumptions and simplifications and so lacks fine details contained in real structures and therefore, cannot give an accurate prediction of filter performance. An equivalent electrical circuit method provides a practically pleasing analysis tool for the representation of the original system and the design of microelectromechanical resonators and filters but it is very difficult to find an equivalent transforming ratio that represents the conversion of acoustic/mechanical energy into electrical energy or vice versa. The representation of the piezoelectric micromachined mechanical filter by mass-spring and equivalent circuit models is hindered by the difficulty in knowing how to represent the finite mass and twisting motion of the mass of the linkage. Furthermore, as the cantilevers are reduced in size and the linkage becomes comparable in size to the resonator beams, the equivalent system approach increasingly fails to give an adequate representation of the structure. The acoustic transmission line model which is the mechanical analogy of the familiar electrical transmission line can be used to model the effective stiffness of the linkage. However, the development of such a model to include the linkage twisting that occurs during operation presents considerable modelling difficulties. FEM is a powerful tool in which an exact structure can be modeled to obtain a complete description of the motions of the structure. It is therefore and appropriate method for predicting the device characteristics of piezoelectric resonators and filters, including the electrical input impedance and mechanical frequency response. However, FEA has not been used to predict the overall performance of linked cantilever filters, including such parameters as the $Q$-value, insertion loss $(I L)$ and ripple, possibly because a suitable modelling approach has not been put forward to date. In this paper, the micro-machined piezoelectrical filter is configured as a two-port device in an electrical circuit and a combined microwave circuit and FEA modelling approach is proposed for the design analysis of the filters and to predict the overall performance. 
This method is very similar to the black box techniques which identify system transfer functions applicable to the modelling of complex systems.

\section{Filter Structure and Operation}

The micro-machined piezoelectric mechanical filters studied here are shown schematically in Figure 1. Two silicon coupled cantilever beams with integrated thin film PZT transducers are mechanically connected by a thin silicon linkage so that an incoming electrical signal is first converted to a mechanical signal by the first beam before being converted back to an output electrical signal by the second. The piezoelectric transducers are capacitive structures composed of lead zirconate titanate $\left(\mathrm{PbZr}_{\mathrm{x}} \mathrm{Ti}_{1} \mathrm{O}_{3}, \mathrm{PZT}\right)$ films sandwiched between top and bottom electrodes. Such a coupled cantilever system exhibits a series of in-phase and out-of-phase vibrational modes, as shown in Figure 1, which are closely spaced in frequency and define the filter pass-band. For the lower frequency mode, both cantilevers vibrate in phase, and for the higher frequency mode, the cantilevers vibrate $180^{\circ}$ out-of-phase. The efficiency of the electromechanical transfer between the two cantilevers depends on the configuration of the small silicon linkage between the two cantilevers, particularly its position with respect to the anchors of the cantilevers. The frequency of operation of the filter is determined by the dimensions of the cantilevers.

\section{Modelling Approach Based on Combined Microwave Circuit and FEA}

A combined microwave circuit [13] and FEA model has been developed for the design of the filters and to predict their performance. A two-port network, shown in Figure 2, represents the coupled cantilevers incorporating the thin film PZT transducers, where End 1 represents the input terminal of one of the cantilevers and End 2 represents the output of the second cantilever. $V_{1}, I_{1}, R_{1},\left(Z_{\text {in }}\right)_{1}$ and $V_{2}, I_{1}, R_{2},\left(Z_{\text {in }}\right)_{2}$ represent the electrical voltages, currents, source resistances and impedances at End 1 and End 2, respectively. 


\subsection{Analysis of the two-port network circuit}

The relationship between the electrical signals at End $1\left(V_{1}, I_{1}\right)$ and End $2\left(V_{2}, I_{2}\right)$ can be written in matrix form as;

$$
\left\{\begin{array}{l}
V_{1} \\
I_{1}
\end{array}\right\}=\left[\begin{array}{ll}
A & B \\
C & D
\end{array}\right]\left\{\begin{array}{c}
V_{2} \\
-I_{2}
\end{array}\right\}
$$

where $A, B, C$ and D represent the generalized electrical parameters of the coupled cantilevers, and are obtainable from the short-circuit admittances as follows:

$$
\left\{\begin{array}{l}
I_{1} \\
I_{2}
\end{array}\right\}=\left[\begin{array}{ll}
y_{11} & y_{12} \\
y_{21} & y_{22}
\end{array}\right]\left\{\begin{array}{l}
V_{1} \\
V_{2}
\end{array}\right\}
$$

where $y_{11}$ is the admittance at End 1 when End 2 is short-circuited, $y_{12}$ is the ratio $I_{1} / V_{2}$ when End 1 is shorted-circuited and a voltage $V_{2}$ is applied at End 2, and $\boldsymbol{y}_{22}$ is the admittance at End 2 when End 1 is short-circuited.

For a reciprocal network and identical cantilevers, the two-port network of the filter is symmetrical so that $A=D$ and

$$
\begin{aligned}
& y_{11}=y_{22} \\
& y_{12}=y_{21}
\end{aligned}
$$

Furthermore, from Eqs. (1) and (2),

$$
A=\frac{-y_{22}}{y_{21}}, B=\frac{-1}{y_{21}}, C=\frac{\Delta y}{y_{21}}, D=\frac{-y_{11}}{y_{21}}
$$

where $\Delta y=y_{11} y_{22}-y_{12} y_{21}$.

As a result, the input impedances at Ends 1 and $2,\left(Z_{i n}\right)_{1}$ and $\left(Z_{i n}\right)_{2}$, are given by

$$
\left(Z_{\text {in }}\right)_{1}=\frac{A Z_{2}+B}{C Z_{2}+D} \text { and }\left(Z_{\text {in }}\right)_{2}=\frac{D Z_{1}+B}{C Z_{1}+A}
$$


and the voltage transfer functions $V_{g} / V_{2}$ by

$$
\frac{V_{g}}{V_{2}}=\frac{A R_{2}+B+C R_{1} R_{2}+D R_{1}}{R_{2}}
$$

where $V_{g}$ is the input voltage.

$S$ parameters are used to measure the performance of a two-port network with terminations $R_{1}$ and $R_{2}$ and can be written as

$$
S=\left[\begin{array}{ll}
S_{11} & S_{12} \\
S_{21} & S_{22}
\end{array}\right]
$$

where $S_{11}$ and $S_{22}$ are the reflection coefficients at Ends 1 and 2, and $S_{21}$ and $S_{12}$ are the transmission coefficients from End 2 to End 1 or from End 1 to End 2, respectively. For any two-port network with resistive terminations, the $S$ parameters are defined as

$$
\begin{aligned}
& S_{j j}=\frac{\left(Z_{i n}\right)_{j}-R_{j}}{\left(Z_{i n}\right)_{j}+R_{j}} \\
& \left.S_{j k}\right|_{j \neq k}=\frac{V_{j}}{\left(V_{j}\right)_{\text {avail }}}
\end{aligned}
$$

where $\left(V_{j}\right)_{\text {avai }}=\frac{1}{2} \sqrt{\frac{R_{j}}{R_{k}}}\left(V_{g}\right)_{k}, \mathrm{k}=1, \mathrm{j}=2$.

Combining Eqs. (4), (5) and (8), $S_{21}$ can be written as

$$
S_{21}=\frac{2}{A+B / R_{2}+C R_{1}+D}
$$

where $R_{l}$ and $R_{2}$ are generally taken to be $50 \Omega$. Therefore, the $\mathrm{dB}$ attenuation for transmission is

$$
I L=20 \log \left|S_{12}\right|(\mathrm{dB})
$$




\subsection{Determination of admittance using FEA modelling}

If the parameters, $y_{11}, y_{12}$ and $y_{22}$, are known, then $S_{21}$ and $S_{11}$ can be clearly determined using Eqs. 8 and 9. By definition, $\quad y_{11}=\frac{I_{1}}{V_{1}}, \quad y_{12}=\frac{I_{1}}{V_{2}} \quad$ and $y_{22}=\frac{I_{2}}{V_{2}}$, where $I_{1}=-j 2 \pi Q_{1} f$ and $I_{2}=-j 2 \pi Q_{2} f$ with $Q_{1}$ and $Q_{2}$ being the charges at Ends 1 and 2, and $f$ the frequency. The voltage and charges generated on the top of the input and output electrodes, $V_{2}$, $Q_{1}$ and $Q_{2}$, can be determined using FEA harmonic analysis. The electromechanical coupled field analysis option within ANSYS (ANSYS Inc. Canonsburg, PA) was used to perform the 3D piezoelectric finite element simulation and to construct the model of the admittances $\left(y_{11}, y_{12}\right.$ and $\left.y_{22}\right)$. This 3D model uses the 8-node, hexahedral, coupled-field element SOLID5 for the piezoelectric materials and the 8-node, linear, structural element SOLID45 for the nonpiezoelectric materials. Voltages of 0 and $1 \mathrm{~V}$ were applied to the top and bottom input electrodes, respectively. Modal and harmonic analyses were performed to determine the series and parallel resonance frequencies for the in-plane and out-of-plane vibrational modes. For the modal analyses, short circuit $\left(V_{l}=0\right)$ and open circuit $\left(Q_{l}=0\right)$ resonance frequencies $f_{s}$ and $f_{p}$ (series and parallel resonance frequencies, respectively) were obtained by solving the constitutive equation subject to the electrical boundary conditions. The harmonic analysis determines a complete spectrum of series and parallel resonance frequencies in the frequency range of interest. It should be noted that the use of the minima and maxima of the electrical input impedance as a measure of the resonance and anti-resonance frequencies is only valid for a piezoelectric material with low loss. However, this method does enable precise visualization of the frequency response of the mechanical filters and is convenient for predicting the filter performance. 
Furthermore, from the definition

$$
Q=\frac{f_{0}}{\Delta f}
$$

where $f_{0}$ is the centre frequency and $\Delta f$ is the bandwidth (BW) of the filter, FEA can be used to calculate Q. Eq. (11) is only applicable to second order band-pass mechanical filters or narrow BW filters.

\section{Design Analysis}

The model described in the previous section was used to investigate the effect of changes in structural parameters on filter characteristics and simulations for several substrate thicknesses and different linkage position, length and width were performed. The results are shown in Figures 4 to 7 and Tables 2 to 5. The material parameters and geometrical dimensions used in the simulations are listed in Table 1 except where specifically mentioned in the text. Since no PZT thin film material data were available from the literature, the bulk values listed in Table1 were used. The material losses in silicon and PZT were simulated by the use of constant damping ratios, $\xi_{\mathrm{s}}$ and $\xi_{\mathrm{p}}$, which are the ratios between the actual damping and critical damping in the harmonic analysis. The $\xi_{\mathrm{s}}\left(\xi_{\mathrm{p}}\right)$ were obtained from the relationship $\mathrm{Q}=\frac{1}{2 \xi_{s}}\left(\frac{1}{2 \xi_{p}}\right)$ with $Q$ values of $10^{5}$ and $10^{3}$ used for silicon and PZT, respectively.

\subsection{Comparison of single and coupled cantilever impedances}

It is interesting to compare the impedance responses of the coupled and single piezoelectric cantilevers. Figure 3 shows the calculated impedances and $S$ parameters versus frequency for single and coupled cantilevers having different linkage positions. The linkage position, $p$, is defined as the distance from the anchor of the cantilever to the linkage normalized to the cantilever length $(L)$, and the results for $p=0.05 L, 0.1 L$ and $0.2 L$ shown in Figure 3. Also shown 
in figure 3 are the results for a single cantilever which reveal minimum and maximum impedances in the calculated response, designated as the positions of the series and parallel resonant frequencies, $f_{s}$ and $f_{p}$, respectively. Using the expression, $Q=f_{0} / \Delta f$ where $f_{0}=\left(f_{p}+f_{s}\right) / 2$ is the central frequency and $\Delta f=f_{p}-f_{s}$ is the $\mathrm{BW}$, the $Q$ of the single piezo-cantilever is about 82 . For the coupled cantilever, there are four peaks in the impedance curve, two minima corresponding to the series resonant frequencies $\left(f_{s i}, f_{s o}\right)$ of the inphase and out-of-phase modes and two maxima corresponding to the parallel resonant frequencies $\left(f_{p i}, f_{p o}\right)$ for the same modes. It can be observed that $f_{s i}$ and $f_{p i}$ are closer in frequency than $f_{s o}$ and $f_{p o}$. It follows that the $Q$-value of the in-phase resonant vibration is higher than that of the out-of-phase vibration for the case where the linkage is close to the anchor. It is worth stressing that the pass-band and the $Q$ of the piezoelectric mechanical filter are determined by $f_{s i}$ and $f_{s o}$ and not by $f_{p i}$ and $f_{p o}$. The $Q$, therefore, of this type of filter is determined by the $Q$ of the in-phase vibration and so, by adjusting the linkage beam position, filters with a high $Q$-value should be attainable.

\subsection{Parametric study}

\section{A. Thickness of the substrate}

Table 2 and figure 4 show that the resonant frequency and $Q$ increase with the increase in silicon substrate thickness $\left(t_{s}\right)$ while the insertion loss $(I L)$ decreases. The behaviour of the resonant frequency is straight forward as it is proportional to $t_{s}^{3}$. $Q$ is inversely proportional to the electromechanical coupling constant $k_{t}^{2}$ but directly proportional to the impedance ratio of the piezo-layer to substrate $Z_{p} / Z_{s}$. Since both of this decrease with the increase of substrate thickness, the $Q$ would be expected to rise. On the other hand, $I L$ is proportional to $k_{t}^{2}$ and $Z_{p} / Z_{s}$, and so it would be expected to decrease. 


\section{B. Linkage}

\section{B.1 Linkage position}

Table 3 and Figure 5 show that $Q$ values can be as high as 1754 with the linkage close to the anchors and as low as 80 when it is away from the anchors (similar to the value obtained for the single piezo-cantilever). Ripples diminishes as the $Q$-value increases, reaching a value of 20.5 $\mathrm{dB}$ at $p=0.2 L$ and dropping sharply to $0.06 \mathrm{~dB}$ at $p=0.05 L$. In contrast, $I L$ maintains almost the same value for the several simulated linkage positions. Since BW is equal to $f_{0} / Q$ and $Q$ is a function of linkage position, the BW of the filter can be set by appropriately positioning the linkage along the main beam without changing its length, width or thickness.

\section{B.2 Linkage length}

Table 4 and figure 6 reveal that the length of the link beam $(l)$ has a small effect on the in- and out-of-phase resonant frequencies but it has a large effect on the $Q$-values ( these can be as high as 3800 for $l=1.2 L$ ) and on the pass-band ripple (about $0.47 \mathrm{~dB}$ for $l<0.4 L$ ). $I L$ is almost constant for $l=0$ to $0.6 L$ but starts to rise for $l>0.6 L$. Therefore, $I L$ and ripple can be minimized if the length of the linkage is designed to be between $0.4 L$ and $0.6 L$.

\section{B.3. Linkage width}

Table 5 and Figure 7 present the results for different linkage widths $(b)$. The results show that $Q$ worsens rapidly as the linkage width is increased and reaches a very low value of 40 when $b=0.1 L$, while the ripple rises abruptly when $b>0.013 L$. $I L$ initially decreases slightly and reaches a minimum value at $b=0.013 L$ and then slightly increases for $\mathrm{b}>0.013 L$. In order to maximize the $Q$-value while minimizing the $I L$ and ripple a value for $b$ of $0.013 L$ seems reasonable. 


\section{Discussion}

The changes in $Q$ due to different linkage dimensions are due to the values of the spring constant of the linkage, $k_{l}$, and the spring constant of the main cantilevers, $k_{r}$ (the mechanical filter's $\left.Q \propto k_{r} / k_{l}\right)$. The closer the linkage is to the anchors, the higher are the values of $k_{r} / k_{l}$ and this explains why a higher $Q$ is obtained when the position of the linkage is close to the anchors. The dependence of the $Q$ on the length and width of the linkage is similarly explained.

\section{2 Dependence of IL on linkage parameters}

The various influences of the linkage parameters on IL can be explained in terms of the electrical and mechanical energy loss of the structure. For any set of linkage parameters, the IL resulting from the electrical energy loss is a fixed value so it is only necessary to consider the effect of the mechanical energy loss on the filter performance. The change in linkage position does not add extra mechanical energy loss to the filter. This is the reason that IL is not affected by the position of the linkage. Lengthening the linkage decreases the coupling stiffness of the linkage and hence increases the strain in the linkage somewhat. Since energy loss is proportional to the square of the strain [11], the increase in linkage length leads to a little higher loss of energy. This is a possible reason that there is only a small rise in IL when the length increases. For the effect of the linkage width on IL, twisting of the linkage is a possible loss mechanism as in this situation the linkage can only transfer a fraction of the energy between the input and output cantilevers. The IL, therefore, increases gradually with increasing linkage width but has a minimum value for $b=0.013 \mathrm{~L}$. A possible reason is that, the coupling stiffness of the linkage is so low that it cannot transfer mechanical energy from one cantilever to another for $b<0.013 L$.

\section{C.3 Pass band frequencies of filters}

From Figure 3, it can be seen that the frequency span of the pass-band can be either higher or 
lower than the series resonant frequency of the single piezo-cantilever, depending on the design of the linkage. The linkage pulls the resonator frequencies apart and creates two closely spaced resonance modes which constitute the ends of the filter pass-bands. For a given cantilever dimension the characteristics of the mechanical filter, including $\mathrm{BW}$, IL, ripple and $Q$, are determined by the linkage.

\subsection{Comparisons between millimetre sized and scaled-down filters}

Figure 8 shows the impedances and $S_{2 I}$ parameters for filters with scaled down dimensions. They are one tenth of the filter dimensions shown in Table 1 except for the linkage width which has the values $1.5 \mu \mathrm{m}, 2 \mu \mathrm{m}$ and $3 \mu \mathrm{m}$. Reduced dimensions give resonant frequencies in the $\mathrm{MHz}$ range because of the higher stiffness of the structure. For a structure having a higher ratio of the resonator stiffness to the linkage stiffness $\left(k_{r} / k_{l}\right)$ a higher $Q$ can be achieved. Because the $k_{r}$ of scaled down filters is much higher than that for large scale filters, it is possible to obtain micro scale filters with much higher $Q$ if precise micro/nano processes are available for the fabrication of the linkage. On the other hand, for micromechanical filters, the resonators and couplers are usually of similar size, and thus, the $k_{r} / k_{l}$ ratio is limited, which limits the attainable $Q$. If a clamped-clamped beam is used, higher $Q$ can be obtained since such a structure has a higher $k_{r} / k_{l}$ ratio than a clamped-free beam with the same dimensions. The reduction in size of the filter results in a higher $I L$. A possible reason for this higher $I L$ is the increase in the electrical impedance $(Z)$ of the transducer since $Z=\frac{t_{p}}{j \omega \varepsilon_{33} A}$, where $\omega$ is the frequency and $A$ is the electrode area. Therefore, a reduction in area leads to a higher $I L$ if the other parameters are kept the same. If the thickness is decreased along with the reduction in filter area, $I L$ can be maintained at a useful low value. 


\section{Conclusions}

A new method for inputting the results of FEA into a microwave circuit has been developed. The method allows parametric design studies of the performance of micro-machined piezoelectric coupled cantilever mechanical filters. The structural dimensions varied were the thickness of the substrate and the position, length and width of the linkage. The performance of the filter has been systematically simulated and discussed. It has been observed that the coupled cantilever filter structures have a significant advantage in terms of increased $Q$. The $Q$ of most filters, such as ladder and array types, is limited by the $Q$ of the individual resonators from which they are constructed. The results show that the coupling linkage not only produces additional resonances but it is also responsible for a significant increase in the quality factor. $Q$ can be very high, if a correct design is implemented. This is not achievable in filters with uncoupled cantilevers.

Regarding the design, the $Q$ value is under the designer's control by a properly configured silicon linkage. The various simulations performed suggest that the optimum design can be achieved for a linkage position close to the anchor point, with length greater than $0.4 L$ and width fixed at 0.013L. Additionally, for higher working frequencies, toward the $\mathrm{MHz}$ region, the simulated results suggest possibly useful performance from scaled down filters. Such devices impose severe requirements on manufacturing the linkage, highlighting the need for nano-structuring of such devices.

Another important feature of the filters is the use of a bending mode in contrast to the thickness mode used in for example FBARs and FBAR filters. This feature makes it possible to fabricate RF MEMS components operating at multiple frequencies on one chip and offers the potential for highly integrated RF MEMS. 


\section{Acknowledgements}

This work was funded by the UK's Engineering and Physical Science Research Council (EPSRC) under Grant No.GR/N06007 and EU Network of Excellence, Advanced MEMS for RF and millimeter Wave Communications (AMICOM). The authors would like to thank Mr. Robert Wright for helpful discussions. The authors are also very grateful for the time the referee has spent on technical issues and for his help in improving the grammatical presentation of the paper. The authors believe the paper has been immensely improved in no small part due to the comments of the referee. 


\section{References}

1) H.P. Loebl, C. Metzmacher, R.F. Milsom, P. Lok, F. Van Straten and A. Tuinhout, RF bulk acoustic wave resonators and filters, Journal of Electroceramics, 12 (2004) 109-118.

2) R. Aigner, J. Ella, H.-J. Timme, L. Elbrecht, W. Nessler, S. Marksteiner, Advancement of MEMS into RF-filter applications, IEEE, IEDM, (2002) 897-900.

3) R. Ruby, P. Bradley, J. Larson III, Y. Oshmyansky, D. Figueredo, Ultra-miniature high- $Q$ filters and duplexers using FBAR technology, IEEE International Solid-state Circuits Conference, (2001) 120.

4) B. Antkowiak, J.P. Gorman, M. Varghese, D.J.D. Carter, A.E. Duwel, Design of a high Q, low-impedance, GHz piezoelectric MEMS resonator, Transducers'03, $12^{\text {th }}$ International Conference on Solid State Sensors, Actuators and Microsystems, Boston, USSA, 2003, pp. 841-846.

5) F.D. Bannon III, J.R. Clark, and C.T.-C. Nguyen, High-Q HF microelectromechanical filters, IEEE Journal of Solid-State Circuit, 35(4) (2000) 512-526.

6) H. Kanbara, H. Kobayashi and K. Nakamura, Analysis of piezoelectric thin film resonators with acoustic quarter-wave multilayers, Jpn. J. Appl. Phys. 39 (2000) 3049-3053.

7) J.F. Rosenbaum, Bulk acoustic wave theory and devices, Boston: Artech House, 1988.

8) J. Southin and R.W. Whatmore, Finite element modeling of nanostructured piezoelectric resonators, IEEE Trans. UFFC, 51(6) (2004) 654-662

9) T. Makkonen, A.Holappa, J.Ella, and M. Saloma, Finite element simulation of thin film composite BAW resonators, IEEE Trans. UFFC, 48(5) (2002) 1241-1258.

10) R.A. Johnson, Mechanical filters in electronics, New York, NY: Wiley, 1983.

11) W.T. Thomson, Theory of vibration with applications, London, George Allen \& Unwin, 1981. 
Meiling Zhu, Paul B. Kirby,

Design study of piezoelectric micro-machined mechanically coupled cantilever filters using a combined finite element and microwave circuit analysis,

Sensors and Actuators A: Physical, Volume 126, Issue 2, 14 February 2006, Pages 417-424.

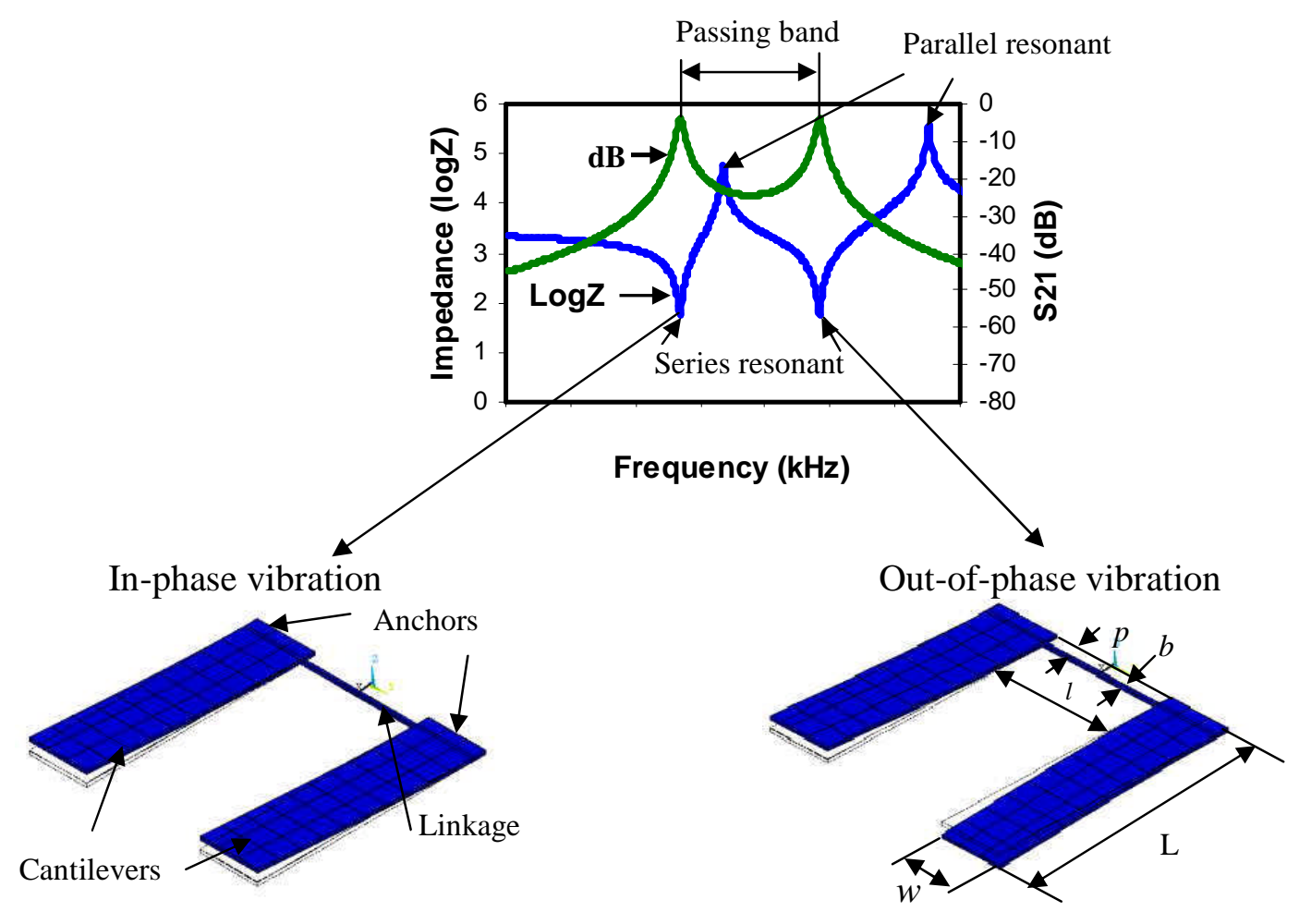

Fig. 1 Piezoelectrically actuated mechanical filters 


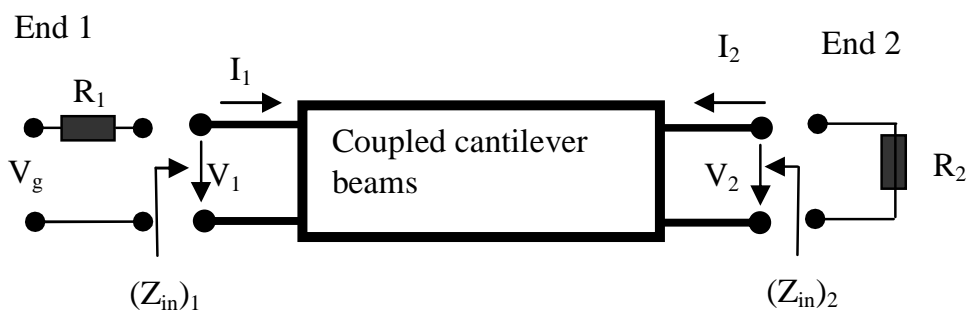

Fig. 2 Analytical model of the filter 


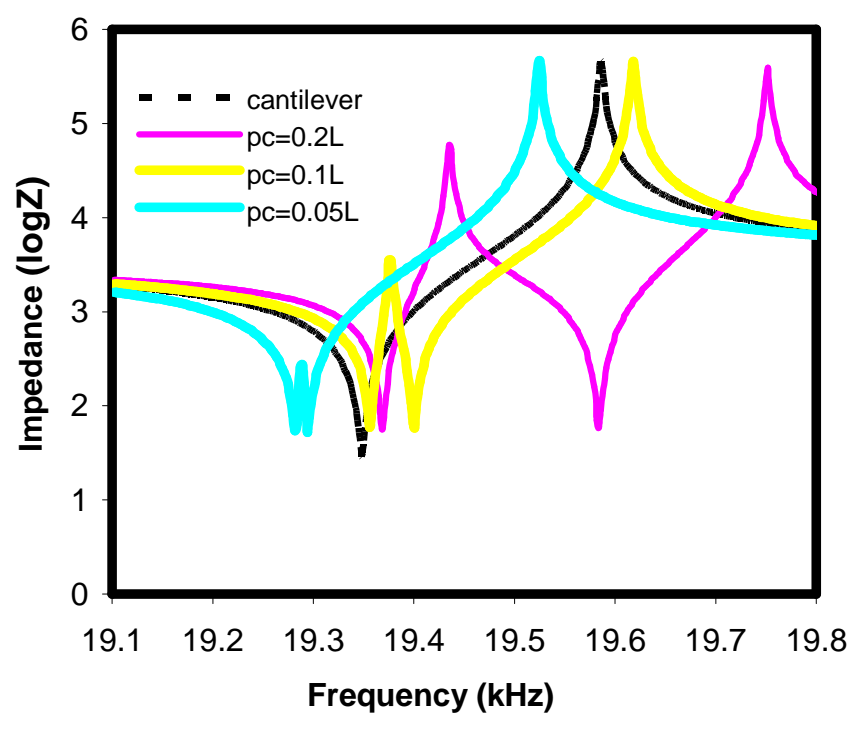

(a)

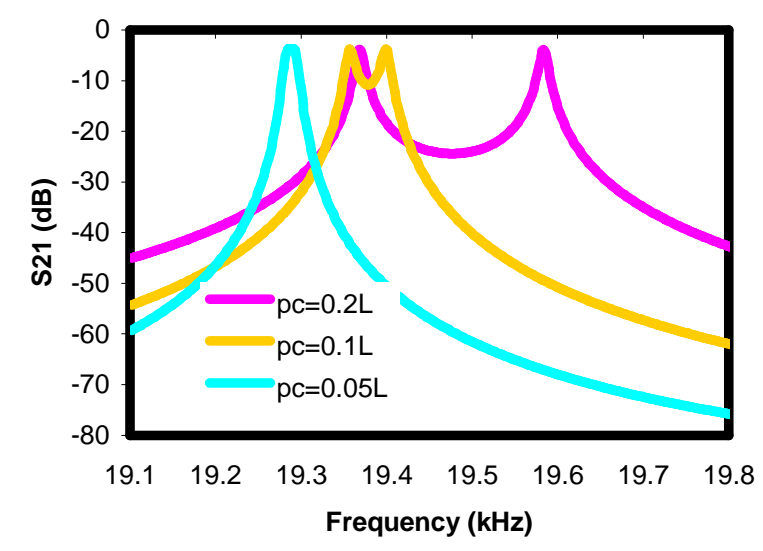

(b)

Fig. 3 Comparison between a single and double piezo-cantilever for different linkage positions: (a) Impedance and (b) $S_{21}$ 


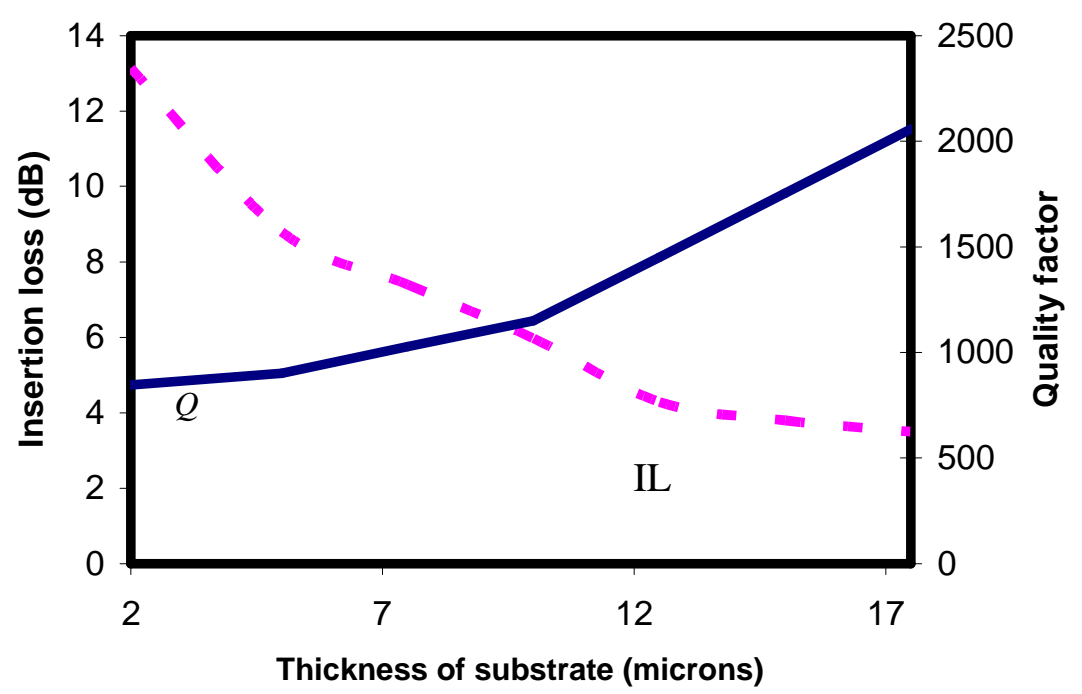

Fig. $4 \mathrm{IL}$ and $Q$ as a function of the substrate thickness 


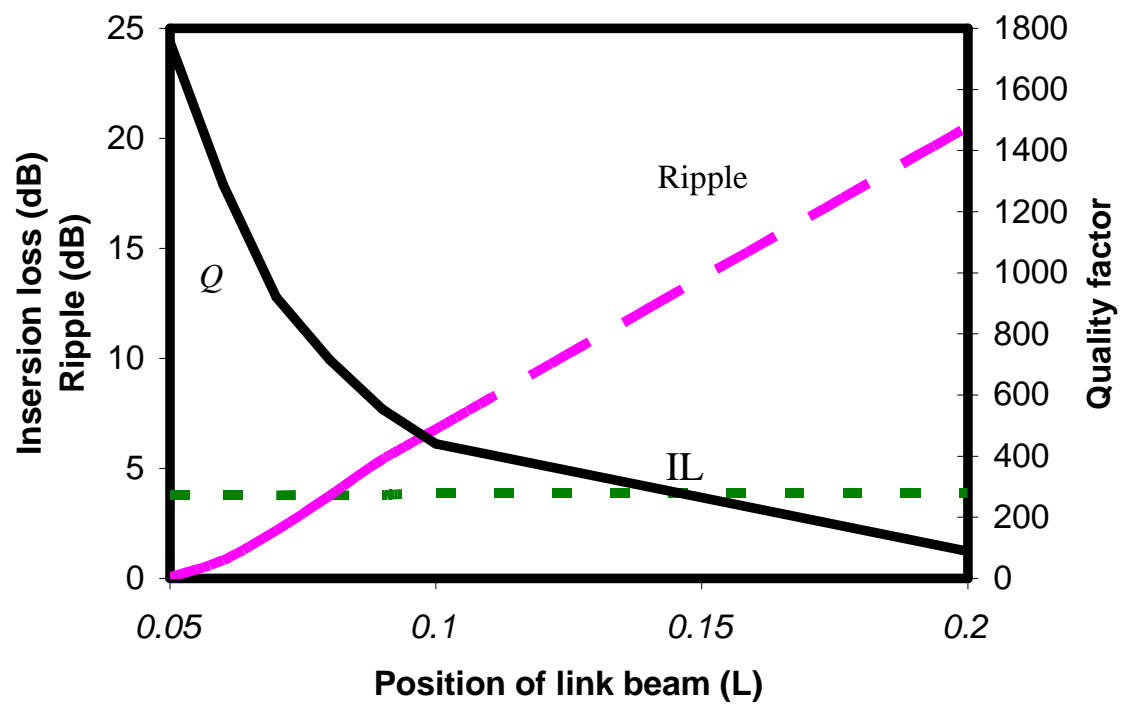

Fig.5 IL, ripple and $Q$ as a function of linkage position 


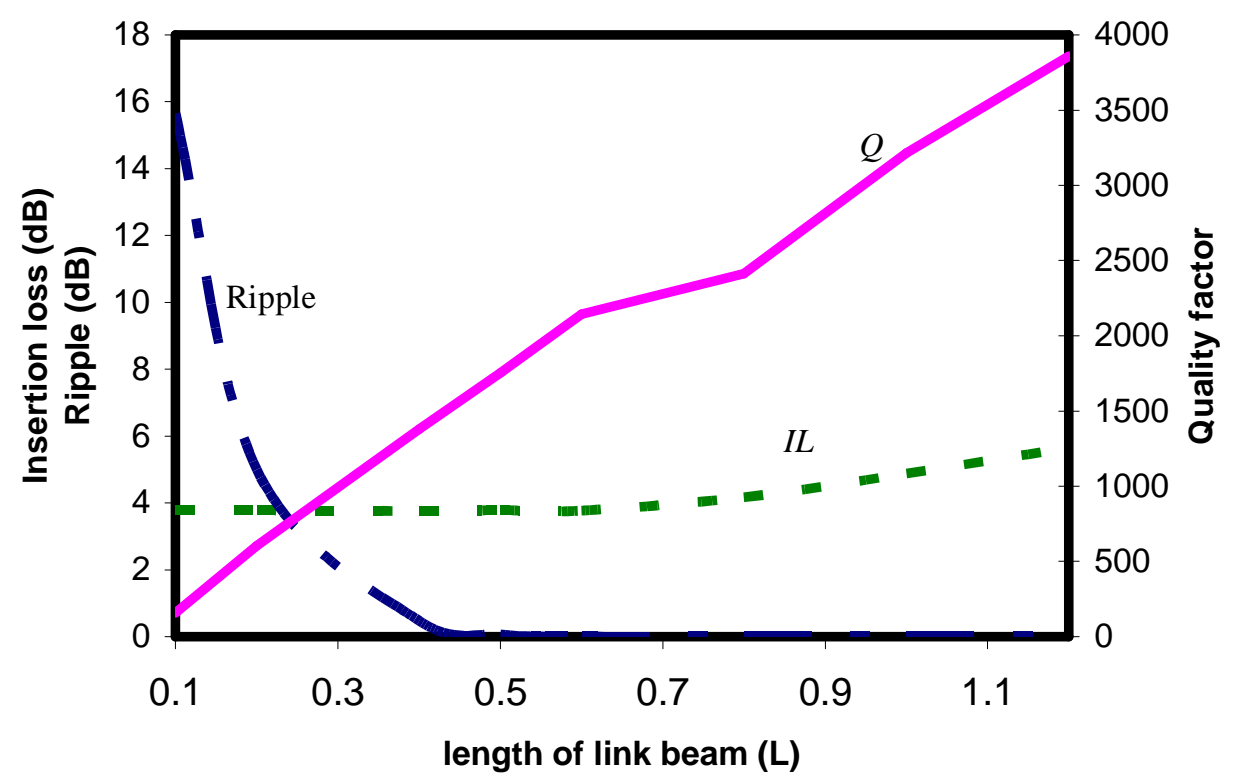

Fig.6 IL, ripple and $Q$ as a function of linkage length 


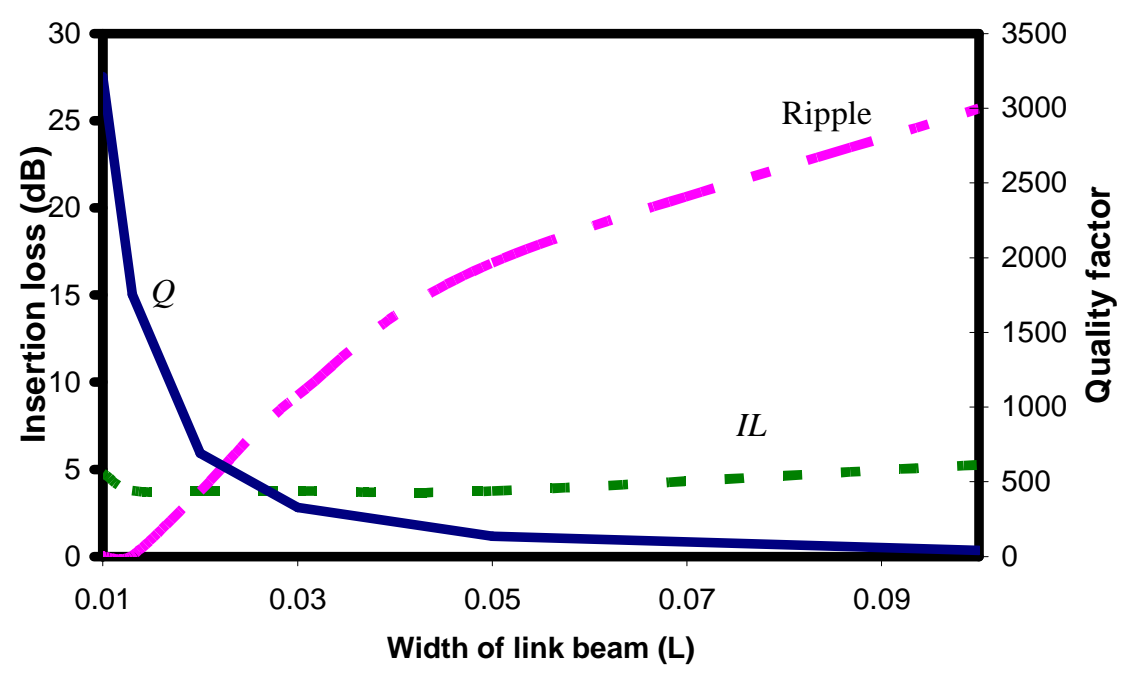

Fig.7 IL, ripple and $Q$ as a function of linkage width 


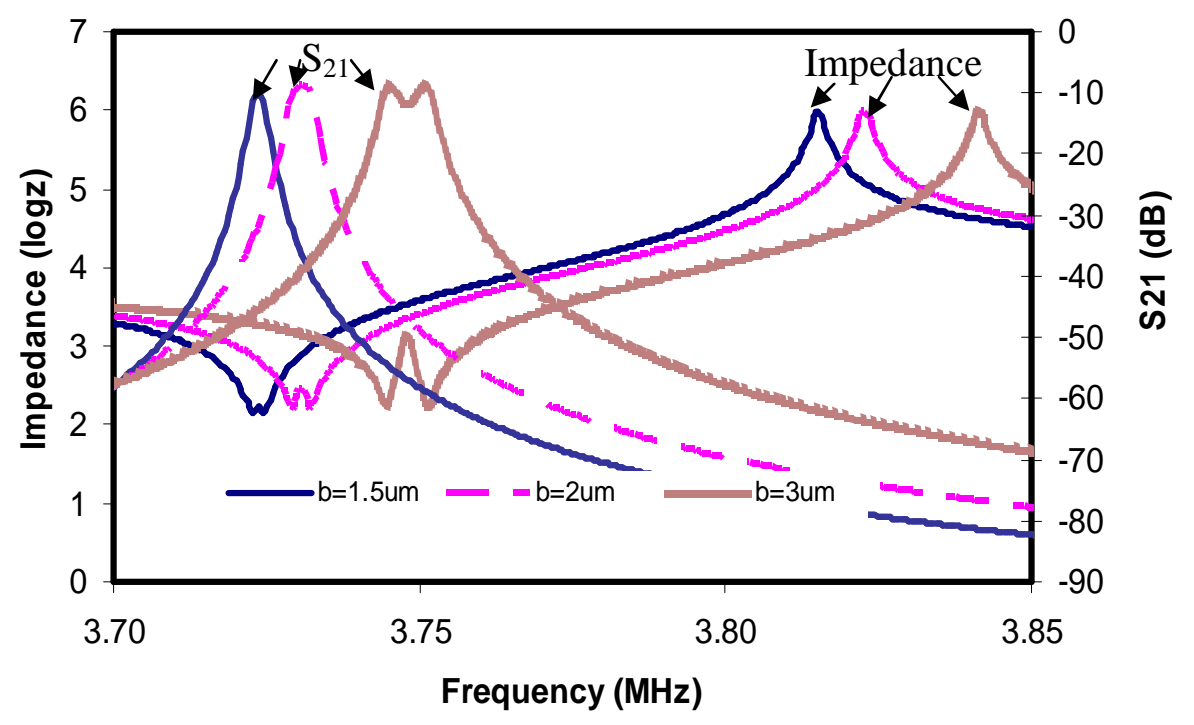

Fig. 8 Impedances and $S_{21}$ of scaled-down filters with different linkage width 
Table 1 Material properties and geometrical dimensions

\begin{tabular}{|c|c|}
\hline Beam length $L(\mu \mathrm{m})$ & 1000 \\
\hline Beam width $w(\mu \mathrm{m})$ & 250 \\
\hline PZT thickness $t_{p}(\mu \mathrm{m})$ & 1 \\
\hline Substrate thickness $t_{s}(\mu \mathrm{m})$ & 15 \\
\hline Linkage length $l(\mu \mathrm{m})$ & $500(0.5 L)$ \\
\hline Linkage width $b(\mu \mathrm{m})$ & $13(0.013 L)$ \\
\hline Linkage position $p(\mu \mathrm{m})$ & $50(0.05 L)$ \\
\hline \multicolumn{2}{|l|}{ Substrate material } \\
\hline Young's modulus $\mathrm{E}_{\mathrm{s}}(\mathrm{GPa})$ & 160 \\
\hline Poisson ratio $\mu_{\mathrm{s}}$ & 0.23 \\
\hline Density $\left(\mathrm{kg} / \mathrm{m}^{3}\right)$ & 2330 \\
\hline Quality factor $\mathrm{Q}_{\mathrm{s}}$ & $10^{5}$ \\
\hline \multicolumn{2}{|l|}{ Piezoelectric material } \\
\hline Young's modulus $\mathrm{C}_{11}(\mathrm{GPa})$ & 148.1 \\
\hline $\mathrm{C}_{12}$ & 98.1 \\
\hline $\mathrm{C}_{13}$ & 107.2 \\
\hline $\mathrm{C}_{33}$ & 146.3 \\
\hline $\mathrm{C}_{44}$ & 25.5 \\
\hline Density $\rho_{\mathrm{p}}\left(\mathrm{kg} / \mathrm{m}^{3}\right)$ & 7850 \\
\hline Piezoelectric constant $\mathrm{e}_{31}\left(\mathrm{Cm}^{-2}\right)$ & -10.84 \\
\hline $\mathrm{e}_{33}$ & 13.68 \\
\hline $\mathrm{e}_{24}$ & 11.56 \\
\hline Dielectric constant $\varepsilon_{11}$ & 1529 \\
\hline$\varepsilon_{33}$ & 759 \\
\hline Quality factor $Q_{p}$ & $10^{3}$ \\
\hline Dielectric loss & 0.01 \\
\hline
\end{tabular}


Table 2 Simulated filter performance for different substrate thicknesses

\begin{tabular}{|c|c|c|c|c|c|c|}
\hline \multirow{2}{*}{$\begin{array}{l}\text { Substrate } \\
\text { thickness } \\
(\mu \mathrm{m})\end{array}$} & \multicolumn{2}{|c|}{ Resonant frequencies } & \multirow{2}{*}{$\begin{array}{l}\text { Band } \\
\text { width } \\
(\mathrm{Hz})\end{array}$} & \multirow[b]{2}{*}{$Q$} & \multirow{2}{*}{$\begin{array}{l}\text { Insertion } \\
\text { loss }(\mathrm{dB})\end{array}$} & \multirow{2}{*}{$\begin{array}{l}\text { Ripple } \\
\text { (dB) }\end{array}$} \\
\hline & $\begin{array}{l}\text { In-phase } \\
\text { mode }(\mathrm{kHz})\end{array}$ & $\begin{array}{l}\text { Out-of- phase } \\
\text { mode }(\mathrm{kHz})\end{array}$ & & & & \\
\hline 2 & 2.5332 & 2.5365 & 3 & 845 & 13.14 & \\
\hline 5 & 6.1338 & 6.1406 & 6.8 & 902 & 8.8 & 1.77 \\
\hline 7.5 & 9.3497 & 9.3588 & 9.1 & 1028 & 7.4 & 1.27 \\
\hline 10 & 12.632 & 12.643 & 11 & 1149 & 5.97 & 0.5 \\
\hline 12.5 & 15.948 & 15.959 & 11 & 1449 & 4.29 & 0.33 \\
\hline 15 & 19.283 & 19.294 & 11 & 1754 & 3.8 & 0.06 \\
\hline 17.5 & 22.628 & 22.640 & 12 & 2058 & 3.5 & 0.11 \\
\hline
\end{tabular}


Table 3 Simulated filter performance for different linkage positions

\begin{tabular}{|l|l|l|l|l|l|l|}
\hline \multirow{2}{*}{$\begin{array}{l}\text { Linkage } \\
\text { position } \\
(L)\end{array}$} & \multicolumn{2}{|c|}{ Resonant frequencies } & $\begin{array}{l}\text { Band } \\
\text { width } \\
\left(\begin{array}{l}\text { In-phase } \\
\text { mode }(\mathrm{kHz})\end{array}\right.\end{array}$ & $\begin{array}{l}\text { Out-of-phase } \\
\text { mode }(\mathrm{kHz})\end{array}$ & $\begin{array}{l}\text { Insertion } \\
\text { loss }(\mathrm{dB})\end{array}$ & $\begin{array}{l}\text { Ripple } \\
(\mathrm{dB})\end{array}$ \\
\hline 0.05 & 19.283 & 19.294 & 11 & 1754 & 3.78 & 0.06 \\
\hline 0.06 & 19.296 & 19.311 & 15 & 1287 & 3.78 & 0.828 \\
\hline 0.07 & 19309 & 19.330 & 21 & 920 & 3.78 & 2.18 \\
\hline 0.08 & 19322 & 19.349 & 27 & 716 & 3.79 & 3.75 \\
\hline 0.09 & 19344 & 19.379 & 35 & 553 & 3.79 & 5.42 \\
\hline 0.10 & 19356 & 19.400 & 44 & 440 & 3.88 & 6.79 \\
\hline 0.20 & 19.364 & 19.584 & 220 & 89 & 3.89 & 20.53 \\
\hline
\end{tabular}


Table 4 Simulated filter performance for different linkage lengths

\begin{tabular}{|l|l|l|l|l|l|l|}
\hline $\begin{array}{l}\text { Linkage } \\
\text { length } \\
(L)\end{array}$ & \multicolumn{2}{|c|}{ Resonant frequencies } & $\begin{array}{l}\text { Band } \\
\text { width } \\
(\mathrm{Hz})\end{array}$ & $Q$ & $\begin{array}{l}\text { Insertion } \\
\text { loss }(\mathrm{dB})\end{array}$ & $\begin{array}{l}\text { Ripple } \\
(\mathrm{dB})\end{array}$ \\
\hline 0.1 & 19.295 & 19.417 & 122 & 159 & 3.79 & 15.65 \\
\hline 0.2 & 19.282 & 19.314 & 32 & 603.5 & 3.785 & 5.0 \\
\hline 0.4 & 19.283 & 19.297 & 14 & 1378 & 3.76 & 0.47 \\
\hline 0.5 & 19.283 & 19.294 & 11 & 1754 & 3.78 & 0.06 \\
\hline 0.6 & 19.283 & 19.292 & 9 & 2143 & 3.77 & 0 \\
\hline 0.8 & 19.282 & 19.290 & 8 & 2411 & 4.17 & 0 \\
\hline 1.0 & 19.282 & 19.288 & 6 & 3214 & 4.87 & 0 \\
\hline 1.2 & 19.282 & 19.287 & 5 & 3857 & 5.655 & 0 \\
\hline
\end{tabular}


Table 5 Simulated filter performance for different linkage widths

\begin{tabular}{|c|c|c|c|c|c|c|}
\hline \multirow{2}{*}{$\begin{array}{l}\text { Linkage } \\
\text { width } \\
(L)\end{array}$} & \multicolumn{2}{|c|}{ Resonant frequencies } & \multirow{2}{*}{$\begin{array}{l}\text { Band } \\
\text { width } \\
(\mathrm{Hz})\end{array}$} & \multirow[t]{2}{*}{$Q$} & \multirow{2}{*}{$\begin{array}{l}\text { Insertion } \\
\text { loss }(\mathrm{dB})\end{array}$} & \multirow{2}{*}{$\begin{array}{l}\text { Ripple } \\
\text { (dB) }\end{array}$} \\
\hline & $\begin{array}{l}\text { In phase } \\
\text { mode }(\mathrm{kHz})\end{array}$ & $\begin{array}{l}\text { Out-of-phase } \\
\text { mode }(\mathrm{kHz})\end{array}$ & & & & \\
\hline 0.01 & 19.272 & 19.278 & 6 & 3213 & 4.77 & 0 \\
\hline 0.013 & 19.283 & 19.294 & 11 & 1754 & 3.78 & 0.06 \\
\hline 0.02 & 19.311 & 19.339 & 28 & 690 & 3.75 & 3.75 \\
\hline 0.03 & 19.363 & 19.422 & 59 & 329 & 3.76 & 9.24 \\
\hline 0.05 & 19.519 & 19.663 & 144 & 136.5 & 3.76 & 16.84 \\
\hline 0.1 & 20.092 & 20.593 & 501 & 41 & 5.26 & 25.7 \\
\hline
\end{tabular}

